\title{
A Brief Talk on the Reformation and Construction of Computing Methods Course
}

\author{
Lian Xue $\mathrm{e}^{1, \mathrm{a}^{*}}$ \\ ${ }^{1}$ School of Computer and Computing Science, Zhejiang University City College \\ Hangzhou, 310015, P.R. China \\ $a^{*} x u e l @ z u c c . e d u . c n$ \\ * The Corresponding Author
}

Keywords: Computing methods course; Curriculum construction; Teaching reform

Abstract. This paper discusses some opinion of teaching and the importance of computing methods course. It explores the teaching of the curriculum reform from the syllabus, teaching materials and the construction of network resources, teaching methods and means of experimental teaching system, evaluation system, etc.

\section{Introduction}

Because of the high degree of popularity of information technology, having a certain level of information technology literacy has become an important objective of the quality education in society $[1,2]$. The cross-century talents we cultivate should have strong math ability.

Be good at math to use appropriate methods to establish an appropriate mathematical model and can use computer to deal with and solve practical engineering problem. General math ability has become an indispensable quality of engineering and technical person. With the development of computer and its application, promotion and deepening of various fields of science and technology scientific computing has become the third means of scientific proof besides theoretical deduction and experimental proof. Therefore, as the basis for scientific computing and core part of the contents, the Computing Methods (or numerical analysis) has been widely used in various fields of scientific technology and the national economy $[3,4]$. Such as oil exploration and development, spacecraft design and control, large-scale water conservancy project design and building, the calculation of the reactor, weather forecasting and storm surge prediction.

Why is Computing Methods widely used? On the one hand, because Computing Methods the basic theory of practical problems of numerical simulation design-analysis and software implementation. On the other hand, because of the development of computer, Computing Methods has been allowed to own advanced computing tools and computing power's improving makes the numerical calculation becomes a reality. The talents cultivate has become one of the objectives of Chinese Universities and scientific research institutions. The Computing Methods course has become a professional required course of mathematics department and various types of applied sciences. Nowadays, numerical calculation is inevitably needed whether in traditional fields or high-tech fields [5,6]. In particular, numerical simulations have become an important means to replace the costly real experiment.

\section{The Significance of Curriculum Construction}

Computing methods is based on the theory of basic math, it use computer to calculate and study up on the computer to solve math problems. It main study numerical calculation, Generally include the following aspects: numerical error analysis, numerical differentiation and integration, roots of nonlinear equations approximate solution, numerical solution of equations, interpolation and fitting, the numerical solution of differential equations, etc. 
This class is mainly for teaching students the thinking way of some classic algorithm generation, improvement and development. Understanding the basic knowledge of modern science and engineering calculation, cultivate the ability of using numerical algorithm as well as the ability of using computer to solve practical problems. Therefore it is a theoretical and practical curriculum.

The curriculum focused on theoretical part of methodological rigor at the view of teaching system from the existing. The computing method is method of using computer to solve approximate solution for math problem. Thus the curriculum has a strong practicality. The future goal is to cultivate the development of application-oriented talents, strengthen the capacity of students in hands-on experience. Therefore the purpose of construction of the curriculum should not only be theory-driven, but also for practical, experimental, and combined with the content of curriculum introduce the subjects' latest progress.

We should Add a variety of assessment methods in its future construction, increasing the time for students hands-on experience and design to increase the idea of computer practice. Also in the teaching process of this curriculum, we need to change the current traditional teaching methods, combining of writing on the blackboard and multi-media technology. At the process of teaching the curriculum we try to combine teaching and the use of computer functions together to stimulate the interest of students.

Therefore the purpose of building a curriculum should not be theory-driven; we could take the practical, experimental into account. Strengthen the teaching experiment; cultivate students' practical ability and innovative ability. We should try to effort to reform teaching methods and teaching methods and improve students' general ability of math. And encourage outstanding students to develop innovative.

\section{Curriculum Improvement}

The traditional methods of computing methods focus on the aspects of theoretical rigor and integrity and downplay the relevance and the technical features of the experimental. Nowadays the curriculum in construction, the curriculum emphasis should be based on the professional orientation of students .We can make the content of the curriculum divided into part A (algorithm, steps, machine implementation and some simple theory) and part B (Algorithm stability, convergence, error analysis of in-depth).Part A mainly face to engineering students, part $A+B$ mainly face to information and Computing Science, as well as science students.

The existence, convergence and stability in the theoretical part of computing methods is still the center of curriculum, at the same time students should get up steps and the process of problem solution by computer. In the face of engineering students, we should make the computing methods which can select true calculation object be the primes and mainly understanding of computing principles and grasp the logic structure of calculation. And it's supposed to desalt the evidence of mathematical theory, strengthen the numerical methods and computer technology training, cultivate and training capacity of numerical approximate calculation and can be applied together to the respective field.

\section{Materials and the Construction of Network Resources}

According to the students' profession, we select the appropriate teaching materials and reference books to adapt in various professional materials, exercise books, laboratory manuals and guidance. In the preparation of teaching materials, we can focus on basic design ideas of computing methods, reflecting the principle and calculation algorithm implementation are equally important. Seeing the manually demonstration as the means and effective and efficient computer calculation as the goal is the philosophy. All methods are given complete MATLAB experimental procedures. Introduction of the concept principle is simple and intuitive. Each type of problem solution starts from the most natural 
thinking way. Try to avoid the direct use of complex theory and principle. It just uses the knowledge of basic calculus and linear algebra and elementary mathematical.

We use network resources to set up calculation of study website. Including syllabus, teaching curriculum vitae, teaching lesson plans, after-school exercise answers, experimental manual, the analog papers with tips and answers and the report of best students. It provides a teaching resource to selfstudy and review for students.

\section{Teaching Methods and the Improving of Measures}

From the characteristics of this class, it put emphasis on cultivating students' ability of researching and mining the essence, and too much in turn, strengthens the multi-media teaching math that might weaken the cultivation of basic cultivation. So we need to be constantly trying to make rational use of multimedia and other new technologies in teaching. During lecturing the course, according to the teaching content and the demand of students' quality, we should combine the traditional teaching methods with modern teaching means, mainly on the blackboard-based lectures, with flexibility in the use of multimedia technology.

Making the "computing methods" multimedia courseware which is knowledge ability, instructiveness, interesting and easy to understand and memorize, and contains the "background knowledge seminars, program design presentations, classroom exercises". Starting from the practical application, enhancing students' interesting by using of the historical background, project examples, pictures, courseware animation and the current popular educational software. Combined the traditional teaching content of the basic course with the current combination of the latest research results. Unifi sing the classroom teaching and extra-curricular counseling, to enable the teaching content of the computing methods to be updated, enrich and strengthen. Changing "teacher-centered" to "studentcentered" pedagogy of the transposition, Changing the "teacher-led" education model defects, promoting the interaction between teaching and learning actively, improving students' learning initiative and enthusiasm, training Students' thinking and innovative ability, organizing students to participate in the teaching-related research projects and mathematical competition, combining the knowledge learned from books with practice. At the same time, through the network knowing the students' learning situation, making lectures from the classroom to the Outside of the classroom, and strengthening the contact of teachers and students.

\section{Experimental Teaching System Reform}

Experimental courses are the important practical aspect of the computing methods course. First of all, strengthen the teaching aspect of the experimental courses. The teachers who are special responsibility for the experimental teaching will advise their students 'internship. Secondly, updating the experimental teaching content and reducing validation experiment, increasing the experimental design, comprehensive experiment and research experiment, forming the teaching system of basic experiment experiment design - research experiment.

\section{Evaluation System Reform}

Reforming the homework method of the computing methods, to classroom test from time to time and exercise on the computer in peacetime mainly, emphasis the content of assessment at ordinary times and at the end and make the marking standard, Usually through the layout of exercise on the computer and some by self-chosen, increasing the time of students' practice, improving the calculation of practical ability of students. 


\section{References}

[1] Z.C.Shi, The Third Scientific Method- Scientific Computation in the Computing time, Tsinghua University Press, Beijing, 2000.

[2] Z.Li, Application of Math Experiment in the University Mathematics Teaching, Neijiang Technology, 28(2007)11-14.

[3] Q.Fu, A Brief Talk on the Students General Ability of Cultivating, Higher Engineering Education Research, 12(2002)86-88.

[4] D.Kincaid, Numerical Analysis :Mathematics of Scientific Computing, Tsinghua University Press, Beijing, 2003.

[5] R.L.Burden, J.D.Faires, Numerical Analysis, Higher Education Press, BeiJing, 2001.

[6] C.N.Yang, On the application of math teaching and research, Yang Zhenning Speech Set, Nankai University Press, TianJin, 1985. 